\title{
DERANGEMENTS OF PULMONARY FUNCTION TESTS;
}

\section{Arterial blood gases in asthmatics after exercise}

\section{Dr. Qamar Mehboob, Dr. Muhammad Arif}

ABSTRACT: Introduction: Asthma is one of the commonest diseases not only in Pakistan but also worldwide. Study Design: This is cross-sectional analytical study. Settings: The study was carried out at Chest Department Civil Hospital Faisalabad. Duration: (Six months) Sep 2011 to Feb 2012. Material and methods: The effects of exercise in asthmatic patients as revealed by their pulmonary function tests(PFT's) and arterial blood gas(ABG) analysis.: Total sixty male subjects having age from thirty to forty years were included. They were divided into experimental and control groups, each consisting of thirty cases. In experimental group all asthmatic patients were included who have been diagnosed six months earlier. Results: The results of PFT's and ABG were recorded and compared, during pre and post exercise periods. At rest there was non-significant difference of PFT's and ABG in two groups. After six minutes exercise on bicycle-ergometer, there was a significant decrease in Forced Expiratory Volume during first second $\left(F E V_{1}, P=0.026\right)$, Forced vital capacity ( FVC, $\mathrm{P}=0.036)$, Partial Pressure of Oxygen $\left(\mathrm{PaO}_{2}, \mathrm{P}=0.036\right)$ and Partial Pressure of Carbondiaoxide $(\mathrm{PaCO}, \mathrm{P}=0.020)$ in asthmatics. Conclusions: We concluded that in response to exercise challenge in asthmatics, PFT's have more precision for assessment than $A B G$.

Key words: Asthma, exercise, pulmonary function test, arterial blood gases.

Article Citation

Mehboob Q, Arif M. Derangements of pulmonary function tests; Arterial blood gases in asthmatics after exercise. Professional Med J 2013;20(2):250-255.

\section{INTRODUCTION}

Asthma is a tremendous health problem not only in Pakistan but also worldwide. "Asthma" is derived from a Greek word meaning "Panting". Asthma is a variable disease, and various factors can lead to an increase (or decrease) in asthma symptoms and the level of asthma control ${ }^{1}$. The airways become sore and swollen and may show increased sensitivity to any specific irritating or allergic substance. When the person inhales such substance bronchoconstriction occurs due to allergic reaction between allergen and $\operatorname{lgE}$. Basophils and mast cells are activated and release certain chemicals (leucotrienes, prostaglandins etc) which cause further inflammatory cell infiltration with neutrophils, eosinophils and lymphocytes(especially $\mathrm{T}$ lymphocytes). Hypertrophy of bronchial smooth muscles occurs. Hypertrophy of the mucus glands makes the condition worse with excessive mucous secretions. So that bronchioles further get narrower and lungs get less air. The great bronchial obstruction increases work of breathing. Expiration becomes more difficult than inspiration and patient exerts increased effort to exhale. In doing so he also uses his chest muscles. In chronic cases chest become "Barrel" shaped.

\section{Review of literature}

Asthma was first recognized in ancient Egypt and named by Hippocrates circa450 BC. Its etiology was considered to be psychological, with treatment often based on psychoanalysis and other 'talking cures'. As these psychoanalysts interpreted the asthmatic; wheeze as the suppressed cry of the child for its mother, they considered that the treatment of depression was especially important for individuals with asthma. Among the first papers in modern medicine published on the subject are one published in1872, which concluded that asthma can be cured by rubbing the chest with chloroform liniment and one in 1873, which tried to explain the pathophysiology of the disease ${ }^{2}$. Current estimates suggest that as many as 300 million people worldwide have asthma and atopy ${ }^{3}$. Adult asthma symptoms typically include shortness of breath and puffing. More often the symptoms are 
caused by allergic substances ranging from animal dander to air pollution. Junking allergic substances is the first step in controlling asthma ${ }^{4}$. However In workrelated asthma, symptoms have correlation with the work and usually worse on working days and improve when the person is away from the workplace - on the weekend, days off and during vacations ${ }^{5}$.

A high level of physical fitness does not confer immunity from asthma. U.S. woman basketball player, Tamika Catchings, an asthma sufferer, won a gold medal in 2004 Olympic games and 21\% of British athletes in these games were confirmed asthmatics. Studies of Finnish elite track and field athletes report physician-diagnosed asthma in 17\% of long-distance runners, $8 \%$ of power athletes, and $3 \%$ of nonathletic controls, while $35 \%$ of figure skaters showed a significant increase in airway resistance following skating routines ${ }^{6}$.

\section{Effects of Exercise on Asthma}

Exercise has a great impact on every person's health including asthmatics. Asthmatics who avoid exercise due to belief that it is bad for their health have been corrected by a study that looked at regular exercise undertaken by a group of asthma sufferers. The results showed an improvement in lung and heart function and more effective ventilation of their lungs, with no exacerbation of asthma symptoms, such as wheezing. It is better that a doctor should be consulted before asthmatics formulate an exercise plan, particularly for those who suffer from exercise-induced asthma ${ }^{7,8}$.

\section{METHODOLOGY}

\section{Aims and 0 bjectives}

According to the research plan the aims of this study were following.

1. To record the arterial blood gases and pulmonary function tests in asthmatic patients who have been diagnosed six months earlier.

2. To compare asthmatics with control group of age and sex matched subjects .

\section{Study Design}

This was cross-sectional analytical study.

\section{Settings}

The study was carried out at Chest Department Civil Hospital Faisalabad.

\section{Study duration}

The study duration was six months.

\section{Sample Size}

A total number of 60 subjects were taken and divided into two groups as follows:

\section{Experimental}

30 male asthmatic patients.

\section{Control}

30 male healthy subjects.

\section{INCLUSION CRITERIA}

- $\quad$ Thirty to forty years male subjects.

- $\quad$ Asthmatics with duration of disease more than six months.

- None of the subjects of both groups will be suffering from any neurological or other medical disorder. This will be assessed by the history and general physical examination .

- $\quad$ Normal respiratory status as assessed by detailed systemic examination.

- $\quad$ Subjects not taking any drug.

\section{EXCLUSION CRITERIA}

- $\quad$ Patients with a history of ischemic heart disease ,chronic renal failure, hypertension , chronic obstructive pulmonary disease, diabetes mellitus or any other serious medical disorder.

- $\quad$ Patients with high grade fever or chronic infection. 
- $\quad$ Smokers.

- $\quad$ Subjects with present or past history of any respiratory disorder including surgical intervention also.

- Drug addicts.

\section{MATERIALS AND METHODS}

Informed consent was taken. Detailed present and past medical history and physical examination was done for all subjects of both groups. Pulmonary function tests were performed in standing position on Spirolab (S/N:A23-050.09708,CE0476). Six minutes moderate exercise was performed on bicycle ergometer at speed of $35 \mathrm{Kmph}$ with the resistance load at 05 . Readings were recorded before and after the exercise. Levels of exercise intensity was assessed according to Weight Watchers ${ }^{9}$.

Arterial sample was taken in a heparinised glass capillary tube. Measurements of arterial $\mathrm{PO}_{2}, \mathrm{PCO}_{2}$ were done by immediately introducing blood sample into blood gas analyzer (model: 348,SN:6139). Dyspnea was assessed according to modified Borg scale $^{10}$.

\section{RESULTS}

\begin{tabular}{|c|c|c|c|c|}
\hline & \multicolumn{2}{|c|}{ Before Exercise } & \multicolumn{2}{|c|}{ After Exercise } \\
\hline & $\begin{array}{l}\text { Control } \\
(\mathrm{N}=30)\end{array}$ & $\begin{array}{l}\text { Experimenta } \\
\text { I }(\mathrm{N}=\mathbf{3 0})\end{array}$ & $\begin{array}{l}\text { Control } \\
(\mathrm{N}=30)\end{array}$ & $\begin{array}{l}\text { Experimental } \\
(\mathrm{N}=\mathbf{3 0})\end{array}$ \\
\hline Mean $\pm S D$ & $2.16 \pm 0.22$ & $1.64 \pm 0.25$ & $2.10 \pm 0.03$ & $1.72 \pm 0.13$ \\
\hline P-value & \multicolumn{2}{|r|}{0.30} & \multicolumn{2}{|r|}{0.02} \\
\hline
\end{tabular}

\begin{tabular}{|l|c|c|c|c|}
\hline \multirow{2}{*}{} & \multicolumn{2}{|c|}{ Before Exercise } & \multicolumn{2}{c|}{ After Exercise } \\
\cline { 2 - 5 } & $\begin{array}{c}\text { Control } \\
\mathbf{( N = 3 0 )}\end{array}$ & $\begin{array}{c}\text { Experimenta } \\
\mathbf{I}(\mathbf{N}=\mathbf{3 0})\end{array}$ & $\begin{array}{c}\text { Control } \\
(\mathbf{N}=\mathbf{3 0})\end{array}$ & $\begin{array}{c}\text { Experimental } \\
(\mathbf{N}=\mathbf{3 0})\end{array}$ \\
\hline Mean \pm SD & $2.02 \pm 0.33$ & $1.81 \pm 0.32$ & $2.03 \pm 0.21$ & $1.88 \pm 0.35$ \\
\hline P-value & \multicolumn{2}{|c|}{0.56} & \multicolumn{2}{|c|}{0.03} \\
\hline & \multicolumn{3}{|c|}{ Table-II. FVC of the study groups } \\
\hline
\end{tabular}

\begin{tabular}{|l|c|c|c|c|}
\hline \multirow{2}{*}{} & \multicolumn{2}{|c|}{ Before Exercise } & \multicolumn{2}{c|}{ After Exercise } \\
\cline { 2 - 5 } & $\begin{array}{c}\text { Control } \\
\mathbf{( N = 3 0 )}\end{array}$ & $\begin{array}{c}\text { Experimenta } \\
\mathrm{I}(\mathbf{N}=\mathbf{3 0})\end{array}$ & $\begin{array}{c}\text { Control } \\
\mathbf{( N = 3 0 )}\end{array}$ & $\begin{array}{c}\text { Experimental } \\
\mathbf{( N = 3 0 )}\end{array}$ \\
\hline Mean $\pm S D$ & $1.09 \pm 0.27$ & $0.94 \pm 0.29$ & $1.05 \pm 0.17$ & $0.98 \pm 0.26$ \\
\hline P-value & \multicolumn{2}{|c|}{0.72} & \multicolumn{2}{|c|}{0.20} \\
\hline
\end{tabular}

\begin{tabular}{|l|c|c|c|c|}
\hline \multirow{2}{*}{} & \multicolumn{2}{|c|}{ Before Exercise } & \multicolumn{2}{c|}{ After Exercise } \\
\cline { 2 - 5 } & $\begin{array}{c}\text { Control } \\
(\mathbf{N}=\mathbf{3 0})\end{array}$ & $\begin{array}{c}\text { Experimenta } \\
\mathrm{I}(\mathbf{N}=\mathbf{3 0})\end{array}$ & $\begin{array}{c}\text { Control } \\
\mathbf{( N = 3 0 )}\end{array}$ & $\begin{array}{c}\text { Experimental } \\
(\mathbf{N}=\mathbf{3 0})\end{array}$ \\
\hline Mean \pm SD & $95.63 \pm 0.21$ & $94.78 \pm 0.44$ & $95.51 \pm 0.10$ & $94.86 \pm 0.24$ \\
\hline P-value & \multicolumn{2}{|c|}{0.19} & \multicolumn{2}{|c|}{0.03} \\
\hline
\end{tabular}

\begin{tabular}{|c|c|c|c|c|}
\hline & \multicolumn{2}{|c|}{ Before Exercise } & \multicolumn{2}{|c|}{ After Exercise } \\
\hline & $\begin{array}{l}\text { Control } \\
(N=30)\end{array}$ & $\begin{array}{l}\text { Experimenta } \\
\qquad \mathrm{I}(\mathrm{N}=\mathbf{3 0})\end{array}$ & $\begin{array}{l}\text { Control } \\
(N=30)\end{array}$ & $\begin{array}{l}\text { Experimental } \\
\qquad(\mathrm{N}=30)\end{array}$ \\
\hline Mean \pm SD & $37.71 \pm 0.45$ & $37.54 \pm 0.34$ & $37.32 \pm 1.07$ & $37.22 \pm 0.10$ \\
\hline P-value & \multicolumn{2}{|c|}{0.12} & \multicolumn{2}{|r|}{0.02} \\
\hline
\end{tabular}

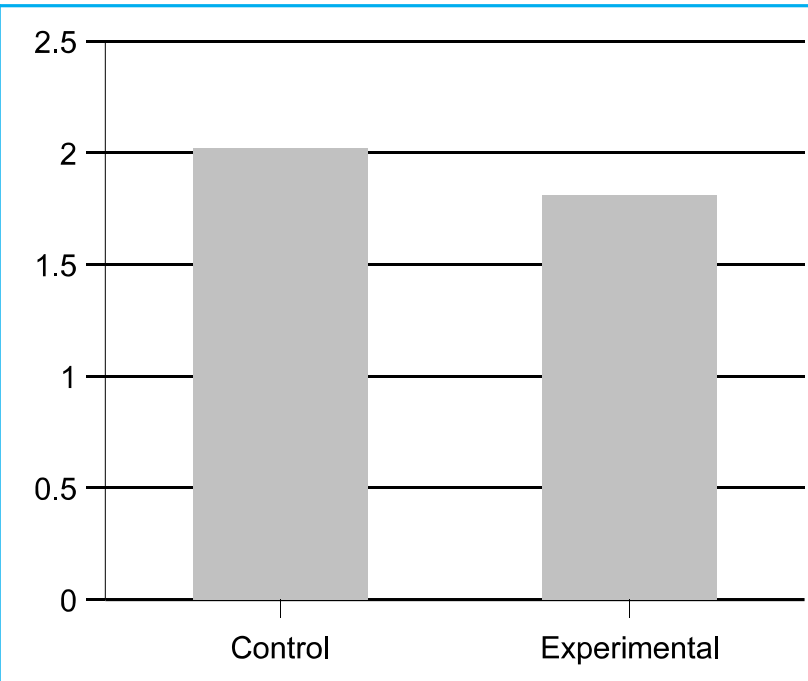

Fig-1. Graphical presentation of FEV $V_{1}$ after exercise 


\section{DISCUSSION}

Breathing is the most vital function for maintenance of life and exercise produces a lot of alterations in normal physiological parameters. The increased metabolic activity during exercise places heavy demands on respiratory and circulatory systems. It causes profound changes in these systems. Basically there is increased demand of the body for $\mathrm{O}_{2}$ and energy and for the removal of $\mathrm{CO}_{2}$ and other metabolic waste products. Any imbalance of these can create functional disturbances.

Asthma is a common lung disease that creates narrowing of the air passages making it difficult to breathe. It can affect the overall quality of life and one's ability to work. When asthma is not managed, it can even threaten the life5.General exercise and specific expiratory muscle training effectively improve respiratory muscle function and reduce sensations of respiratory effort during exercise in nearly all patients with pulmonary disease. This can be achieved by resistance training of the ventilatory musculature with a continuous positive airway pressure device, increasing respiratory muscle force and endurance capacity through regular aerobic exercise training ${ }^{6}$.

So it was planned to conduct a study in which PFTs and arterial blood gases were recorded in asthmatics and compared with normal values. In our present study we compared 30 asthmatics with 30 normal subjects with a mean age of both groups was $34.98 \pm$ 3.68 years, in which the mean ages of experimental group was $34.63 \pm 3.75$ years and the mean ages of control group was $35.33 \pm 3.65$ years. The minimum and maximum ages in years of both groups were noted as 30 \& 40years respectively.

The measurements of airflow obstruction in asthmatics can be done by different methods. Most widely used methods are the measurements of $\mathrm{FEV}_{1}$ and FVC. It is important to realize that these endpoints are not necessarily equivalent because of the complex physiology of the lung and the clinical state of the patient $^{11}$.

The response to six minutes exercise challenge was significant decrease in $\mathrm{FEV}_{1}(\mathrm{P}=0.026)$, FVC $(P=0.036)$. These results reflect increase airway resistance due to bronchocontriction which increases the propensity for expiratory flow limitation and dynamic hyperinflation during exercise in asthmatics when compared with normal subjects. The decrease in these parameters are also reported by Jalusic ${ }^{12}$. In his opinion these values can be increased by decreasing airway resistance. Highly significant decrease in $\mathrm{FEV}_{1}$ in response to exercise was also reported by Guyton ${ }^{13}$.

Calculating the ratio between $\mathrm{FEV}_{1}$ and FVC we get statistically insignificant results similar to the study results of Ratageri ${ }^{14}$. The ratio is particularly helpful in deciding whether a person's lung disease is an obstructive or restrictive type. If the $\mathrm{FEV}_{1} / \mathrm{FVC}$ ratio is lower than expected, this indicates obstruction as in asthma. If the $\mathrm{FEV}_{1} / \mathrm{FVC}$ ratio is normal but the FVC is decreased, this indicates restrictive disease. If both the $\mathrm{FVC}$ and the $\mathrm{FEV}_{1} / \mathrm{FVC}$ are reduced, this may mean that there are both restrictive and obstructive components to the problem. It is possible for a person to have asthma and also have completely normal PFTs. This means that in the absence of an acute asthma attack, the person does not have any airway obstruction ${ }^{15}$.

Mean baseline $\mathrm{PaO}_{2}$ and $\mathrm{PaCO}_{2}$ were also compared in asthmatics and controls. Our results showed significant decrease in $\mathrm{PaO}_{2}$ and $\mathrm{PaCO}_{2}$ values remained statistically insignificant. These results reflects compensatory respiratory alkalosis. Decrease $\mathrm{PaO}_{2}$ in asthmatics after an exercise stress test is also reported by Muneeza ${ }^{16}$ and Rudolf ${ }^{17}$. The fall in $\mathrm{PaO}_{2}$ is mostly due to mismatched ventilation-perfusion ratio. Our results regarding $\mathrm{pCO}_{2}$ differs from the results shown by Terumasa ${ }^{18}$ and Rudolf. In Terumasa'sopinion $\mathrm{pCO}_{2}$ does not change much until 
a very severe degree of airway obstruction is encountered, in which case $\mathrm{PaCO}_{2}$ tends to increase. $\mathrm{He}$ concluded that alveolar ventilation is maintained at a normal level during most asthmatic attacks, but the $\mathrm{PaO}_{2}$ falls in relation to the degree of obstruction, probably because of uneven ventilation. An elevated $\mathrm{PaCO}_{2}$ appears to be an ominous sign. Arterial blood gases need to be taken in the majority of patients with asthma exacerbations, and should be repeated to monitor improvement. The changes in their values are greatly influenced by the type, duration and intensity of exercise and the severity of the disease. Thesevalues alone don't provide enough information to diagnose a problem. For example, they can't tell whether low levels are caused by lung or heart problems. So it is better to review these values with other examinations and tests.

\section{CONCLUSIONS}

1. In response to exercise challenge asthmatics have decrease PFTs and ABG values when compared with normal subjects.

2. PFTs are more reliable than $A B G$ for the diagnosis and assessment of severity of asthma.

3. Serial measurements of these tests should be done to get the best results.

\section{REFERENCES}

1. Barbara $P$ Yawn, Factors accounting for asthma variability: achieving optimal symptom control for individual patients, Primary care respiratory J,17(3) ,Sept 2008, 138-147.

2. Asthma, History; Wikipedia;2012.

3. Christopher H. Fanta, M.D., Asthma, N Engl J Med ,March 5,2009; 360:1002-1014.

4. Joseph Amcotts. A Look At Some of The Symptoms of Adult Asthma; Health and Fitness, 2012; Feb, 2.

5. Ccohs. Is work leaving you breathless? ; Daily News, 2012; Feb 1.
6. William .D Mc Ardle, Frank I.Katch, Victor L. Katch Exercise Physiology, Energy, Nutrition and Human Performance; $6^{\text {th }}$ Edition, Nov, 2009;13(7)970-2.

7. Anonymous. Asthma Prescription to include exercise; New Kerala.com, 2005;22 0ct.

8. Daniel. Can I have Exercise if I have Asthma? About .com. Allergies, 2011; 7 Aug.

9. Exercise Intensity Levels, The Weight Watchers Research Department. Nov 13,2012.

10. Sunita C, Robert M Smith: Usefulness of modified 0-10 Borg scale in assessing the degree of dyspnea in patients with COPD and asthma. J of emergency nursing. June 2000; 26(3):216-22.

11. Charles $\mathrm{G}$. Use of pulmonary function testing in the diagnosis of asthma; 2011;Nov 15.

12. Jalusic-Gluncic. What happens with airway resistance (RAW) in asthma and COPD exacerbation; J Med Arh 2011; 65(5):270-3.

13. Guyton , Hall. Asthma; Text book of Medical Physiology,11th Ed. 2007,529.

14. V H VH Ratageri, S K SK Kabra, V Vseth, Lung function tests in asthma: which indices are better for assessment of severity? J Trop Pediatr, 2001;47(1):57-9.

15. AnnaLoengard. Pulmonary Function Testing Such as Spirometry; About.com Health's Disease and Condition, 2008;February 20.

16. Muniza S, Shahbaz A. Arterial Blood Gases During Exercise Induced bronchoconstriction in asthmatic children. JFJMC. Apr-Jun 2009;3(2):128-32.

17. Rudolf M , Riordan JF, Grant BJ, Maberly DJ, Saunders $\mathrm{KB}$; Arterial blood gas tensions in acute severe asthma, European Journal of Clinical Investigation: 1980;10(1), 55.

18. Terumasa M, Katsuyuki M, Kazuo F. Arterial Blood Gases in Bronchial Asthma, Allergy, 2004;45(4), Nov, 248-254. 


\section{AUTHOR(S):}

1. DR. QAMAR MEHBOOB

MBBS, M.Phil

Assistant Professor,

Physiology department, Independent medical college, Faisalabad.

2. DR. MUHAMMAD ARIF

MBBS, DOMS, FCPS

Senior Registrar,

Ophthalmology Department,

PMC / Allied Hospital, Faisalabad

\section{Correspondence Address:}

Dr. Qamar Mehboob

Assistant Professor,

Physiology department,

Independent medical college,

Faisalabad.

qamarmehboob89@yahoo.com
Article received on: 29/11/2012

Accepted for Publication: $\quad$ 02/12/2012

Received after proof reading: 05/02/2013

\section{PREVIOUS RELATED STUDIES}

Nayla Tariq Chaudry, Imrana Ihsan, Sabiha Nasreen. BRONCHIAL ASTHMA; EFFECT OF ADHATODA VESICA ON AIRWAY RESPONSIVENESS WITH PULMONARY FUNCTION TESTS (Original) Prof Med Jour 12(3) 327-330 Jul, Aug, Sep 2005.

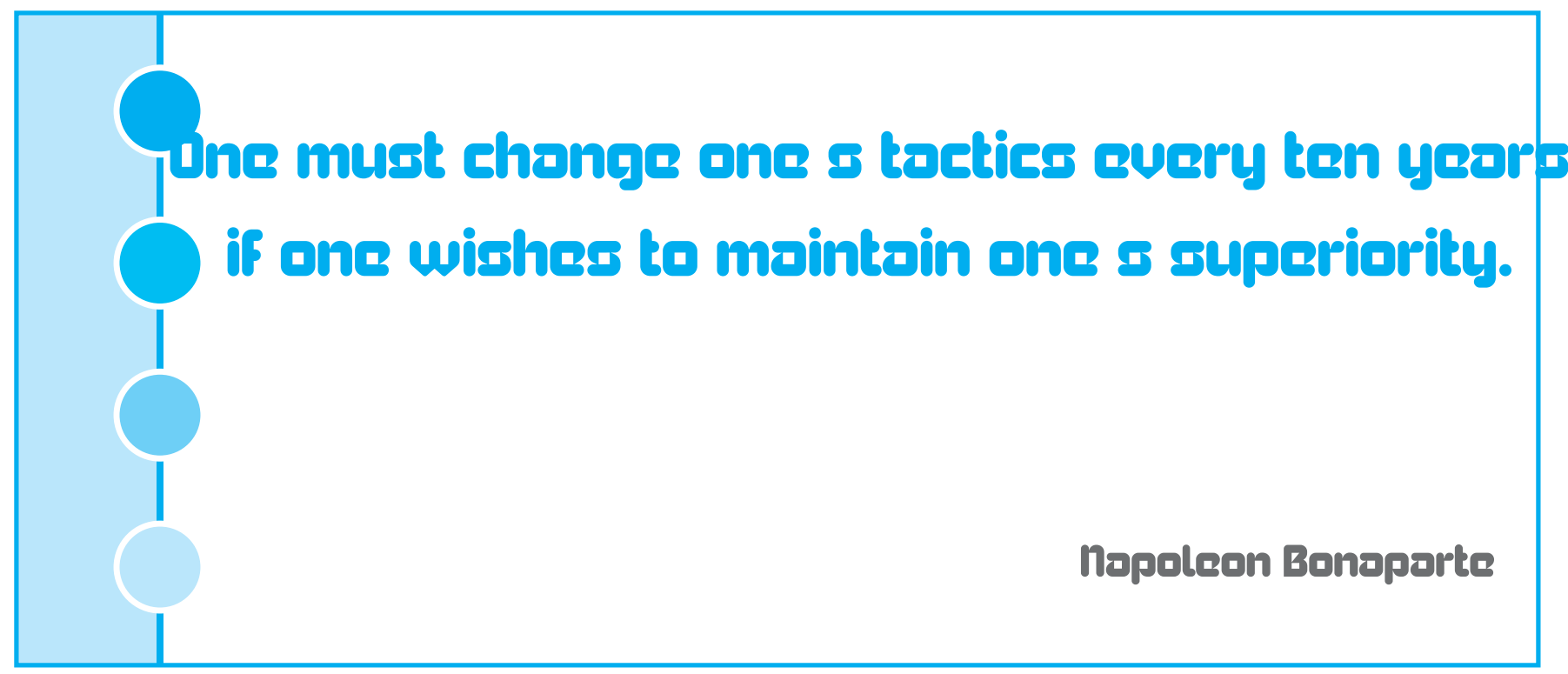

